\title{
Inclusão de grãos de girassol na ração de cordeiros sobre as características quantitativas da carcaça e qualitativas da carne
}

\author{
Inclusion of sunflower seeds in the diet of lambs on carcass \\ quantitative characteristics and meat quality
}

\author{
Sandra Mari Yamamoto ${ }^{1 *}$; Américo Garcia da Silva Sobrinho²; \\ Rafael Silvio Bonilha Pinheiro ${ }^{3}$; André Gustavo Leão"; \\ Daniela Pionorio Vilaronga Castro ${ }^{5}$
}

\begin{abstract}
Resumo
Objetivou-se avaliar as características quantitativas da carcaça, bem como a composição tecidual os cortes da carcaça e qualidade da carne de cordeiros recebendo grãos de girassol na ração. Foram utilizados 21 cordeiros 7/8 Ile de France 1/8 Ideal, não castrados, com peso corporal médio inicial de 17 $\mathrm{kg}$, alojados individualmente e distribuídos em três dietas $(0,7,5$ e $15 \%$ de grãos de girassol na ração) em delineamento experimental inteiramente casualizado decomposto em modelo fatorial $3 \times 2$ (três rações e dois cortes de carcaça). Ao final do período experimental, os animais foram abatidos, obtendo-se os pesos e rendimentos de carcaça quente e fria, além dos rendimentos comercial e biológico da carcaça. As carcaças foram seccionadas longitudinalmente e a meia-carcaça esquerda dividida em seis partes anatômicas, sendo retirado o lombo e a perna para avaliação dos componentes teciduais e características de cor, capacidade de retenção de água, perdas por cocção e força de cisalhamento. Houve diferença para rendimento comercial, com maior valor (46,82\%) para carcaças de cordeiros recebendo ração sem inclusão de grãos de girassol em relação ao rendimento de carcaça $(44,11 \%)$ de cordeiros alimentados com $15 \%$ de grãos de girassol. As proporções de músculo e gordura total, assim como a relação músculo:gordura foram influenciadas $(\mathrm{P}<0,05)$ pela ração, com maior quantidade de músculo $(63,15 \%)$ e menor de gordura $(16,63 \%)$ nos cortes perna e lombo de cordeiros que não receberam grãos de girassol. No corte perna foi observado maiores proporções de músculo $(67,27 \%)$, relação músculo:osso $(4,08)$ e músculo:gordura $(4,92)$ quando comparado ao lombo. O músculo Longissimus lumborum apresentou maior capacidade de retenção de água e menor força de cisalhamento em relação ao músculo Semimembranosus. A inclusão de grãos de girassol na ração de cordeiros em confinamento aumentou a deposição de gordura nos cortes da carcaça, porém não afetou os demais parâmetros qualitativos da carne.
\end{abstract}

Palavras-chave: Helianthus annuus, lombo, maciez, ovinos, rendimento

\begin{abstract}
This study aimed to evaluate the carcass quantitative characteristics, tissue composition of carcass cuts and meat quality of lambs receiving sunflower seeds in the diet. Twenty-one lambs $7 / 8$ Ile de France
\end{abstract}

\footnotetext{
${ }^{1}$ Prof ${ }^{\mathrm{a}}$. do Colegiado de Zootecnia da Universidade Federal do Vale do São Francisco, UNIVASF, Petrolina, PE. E-mail: sandra. yamamoto@univasf.edu.br

${ }^{2}$ Prof. do Dept $^{\circ}$ de Zootecnia da Faculdade de Ciências Agrárias e Veterinárias, UNESP, Jaboticabal, SP. E-mail: americo@fcav. unesp.br

${ }^{3}$ Prof. do Dept ${ }^{\circ}$ de Biologia e Zootecnia da FEIS/UNESP, Campus de Ilha Solteira, SP. E-mail: rafaelsbp@gmail.com

${ }^{4}$ Discente de Pós-doutorado em Zootecnia da Universidade Federal da Bahia, UFB, Salvador, BA. E-mail: agleao@yahoo.com.br

${ }^{5}$ Discente de Mestrado do Programa de Pós-Graduação em Ciência Animal, UNIVASF, Petrolina, PE. E-mail: danipionorio_ zootecnia@hotmail.com

* Autor para correspondência
} 
1/8 Ideal, not castrated, with initial body weight of $17 \mathrm{~kg}$ were housed in individual pens and distributed in three diets $(0,7.5$ and $15 \%$ of sunflower seeds inclusion) in a completely randomized design in 3 x 2 factorial arrangement (three diets and two carcass cuts). At the end of the experimental period, the animals were slaughtered; weights and hot and cold carcass yields and commercial and biological carcass dressing were collected. The carcasses were split lengthways and left half carcass divided into six anatomical parts. The leg and loin were removed for evaluation of tissue composition, meat color, water holding capacity, cooking losses and shearing force. Difference was detected in the commercial carcass yield; with higher value (46.82\% of total weight) for carcasses of lambs fed without sunflower seeds when compared with carcass yield (44.11\%) of lambs fed with $15 \%$ of sunflower seed inclusion. The proportion of muscle and total fat, as muscle:fat ratio were affected $(\mathrm{P}<0.05)$ by feeding, with higher quantity of muscle $(63.15 \%)$ and less fat $(16.63 \%)$ in the leg and loin cuts of lambs fed without sunflower seeds. In the leg was observed higher proportions of muscle (67.27\%), muscle:bone ratio (4.08) and muscle:fat ratio (4.92) when compared with the loin cut. The water retention capacity and shearing force of Longissimus lumborum muscle showed better results when compared with Semimembranosus muscle. The inclusion of sunflower seeds in the diet of feedlot lambs increased the fat deposition in carcass cuts, however did not affect the other parameters of meat quality.

Key words: Carcass yield, Helianthus annuus, lambs, loin, tenderness

\section{Introdução}

A ovinocultura de corte vem apresentando crescente participação sócio-econômica na atividade pecuária do Estado de São Paulo. A produção de carne ovina tem sido estimulada pelo elevado potencial do mercado consumidor dos grandes centros urbanos brasileiros. No entanto, a baixa qualidade das carcaças comercializadas, geralmente provenientes de animais com idade avançada, é o principal fator limitante que influencia o consumo de carne ovina no Brasil (SILVA; PIRES, 2000; GARCIA; PEREZ; OLIVEIRA, 2000). Também há a comercialização de animais jovens com carne de baixa qualidade, pois em muitos casos não são terminados adequadamente em relação à nutrição, ao melhor peso ao abate, à sanidade e ao manejo pré-abate.

O mercado consumidor valoriza carcaças de animais jovens, abatidos com idade inferior a 150 dias e peso corporal entre 28 a $36 \mathrm{~kg}$. A terminação de cordeiros em confinamento pode proporcionar abate precoce dos animais, resultando em carcaças com características que atendam as exigências de mercado, garantindo retorno mais rápido do capital investido (OLIVEIRA et al., 2002). Entretanto, este sistema muitas vezes apresenta balanço econômico desfavorável, em decorrência principalmente da alimentação, responsável por grande parte dos custos de produção. Diante disso, a substituição dos alimentos tradicionais por fontes alternativas é de fundamental importância quando o objetivo é reduzir o custo de produção.

Dentre as culturas agrícolas utilizadas na alimentação animal, a do girassol tem aumentado surpreendentemente sua produção, que outrora, as sementes eram utilizadas principalmente na alimentação de pássaros e a partir 1996, para produção de óleo (ANGELINE et al., 1998). Tal fato foi devido à valorização do óleo, rico em ácidos graxos poliinsaturados $(66 \%)$, principalmente do ácido linoléico, um ácido graxo essencial muito procurado pela população humana por causa dos benefícios à saúde (COLLOMB et al., 2004).

A composição da carcaça nas proporções de músculo, gordura e osso, determina grande parte do valor econômico da mesma. Dentre os componentes teciduais, a gordura está diretamente relacionada com o aspecto qualitativo da carcaça. De acordo com Bueno et al. (2000), as carcaças devem apresentar elevada porcentagem de músculos, gordura subcutânea uniforme e adequada ao mercado consumidor.

A carne é uma complexa organização de músculo esquelético, tecido conjuntivo e gordura, resultante 
de várias reações fisico-químicas a partir do abate, ou mesmo antes deste, e que determinam suas qualidades nutricional e sensorial. Neste contexto, para o mercado ser competitivo é necessário que a carne ovina apresente parâmetros de qualidade desejáveis, tanto quantitativos como qualitativos.

A cor é a uma das primeiras características a ser observada pelo consumidor ao adquirir a carne resfriada, pois indica o seu frescor, influenciando a decisão de aquisição do produto (PELICANO; SOUZA, 2004). O interesse do estudo da capacidade de retenção de água pelo músculo decorre de sua influência no aspecto da carne antes do cozimento e no seu comportamento durante o processo de cocção, tendo como mérito, avaliar a importância da sua participação na suculência do produto (PARDI et al., 2001). A maciez é um fator qualitativo que influencia as características sensoriais da carne (KOOHMARAIE; WHIPPLE; CROUSE, 1990), podendo ser definida como a facilidade de mastigar a carne com sensações de penetração e corte, resistência à ruptura e presença de resíduo.

O objetivo deste trabalho foi avaliar o efeito da inclusão de grãos de girassol em rações para cordeiros terminados em confinamento sobre as características quantitativas da carcaça, bem como a composição tecidual do lombo e da perna e características qualitativas dos músculos Longissimus lumborum e Semimembranosus destes cortes.

\section{Material e Métodos}

O experimento foi realizado no Setor de Ovinocultura, pertencente à Faculdade de Ciências Agrárias e Veterinárias, UNESP/Jaboticabal/SP. Foram utilizados 21 cordeiros 7/8 Ile de France 1/8 Ideal, não castrados, com peso corporal médio inicial de $17 \mathrm{~kg}$, confinados em gaiolas individuais com piso ripado suspenso, equipadas com comedouros e bebedouros.

Os animais receberam rações isoprotéicas, com inclusão de $0 ; 7,5$ e $15 \%$ de grãos de girassol, as quais continham 2,32; 2,41 e 2,48 Mcal de energia metabolizável/kg de matéria seca, respectivamente (Tabela 1). A relação volumoso:concentrado foi de 30:70, sendo utilizado como volumoso feno de Tifton 85, moído em partículas de 3 a $5 \mathrm{~cm}$.

Tabela 1. Composição percentual e bromatológica das rações experimentais.

\begin{tabular}{lccc}
\hline \multirow{2}{*}{\multicolumn{1}{c}{ Ingrediente (\%) }} & \multicolumn{3}{c}{ Ração $^{\mathbf{1}}$} \\
\cline { 2 - 4 } & $\mathbf{R} 1$ & $\mathbf{R 2}$ & $\mathbf{R 3}$ \\
\hline Grão de milho moído & 45,00 & 42,00 & 38,00 \\
Farelo de Soja & 23,00 & 18,50 & 15,00 \\
Calcário & 0,50 & 0,50 & 0,50 \\
Suplemento mineral ${ }^{2}$ & 1,50 & 1,50 & 1,50 \\
Grãos de girassol moído & - & 7,50 & 15,00 \\
Feno de Tifton 85 & 30,00 & 30,00 & 30,00 \\
\hline \multicolumn{1}{c}{ Nutriente } & & & \\
\hline Matéria seca (\%) & 90,83 & 90,25 & 90,73 \\
Matéria mineral (\%) & 5,35 & 5,14 & 5,05 \\
Proteína bruta (\%) & 17,80 & 17,70 & 17,03 \\
Extrato etéreo (\%) & 2,74 & 6,93 & 9,61 \\
Energia metabolizável & 2,32 & 2,41 & 2,48 \\
(Mcal/kg MS) & & \\
\hline
\end{tabular}

${ }^{1} \mathrm{R} 1=$ ração sem graõs de girassol; $\mathrm{R} 2$ = ração contendo $7,5 \%$ de graõs de girassol e R3= ração contendo $15 \%$ de graõs de girassol. ${ }^{2}$ Suplemento mineral: zinco $1.600 \mathrm{ppm}$, cobre 300 ppm, manganês $1.500 \mathrm{ppm}$, ferro $1.100 \mathrm{ppm}$, cobalto $10 \mathrm{ppm}$, iodo $27 \mathrm{ppm}$ e selênio $22 \mathrm{ppm}$.

Fonte: Elaboração dos autores.

Os cordeiros tiveram 15 dias de adaptação às rações fornecidas em duas refeições diárias, às 7 e às 17 horas, com ajuste diário para permitir $20 \%$ de sobras e foram pesados no início do experimento e a cada 14 dias. Ao atingirem $32 \mathrm{~kg}$ de peso corporal, os animais foram submetidos a jejum de sólidos por 16 horas.

Os cordeiros foram pesados (PVA) e posteriormente insensibilizados com descarga elétrica de $220 \mathrm{~V}$ por dez segundos, e em seguida, seccionaram-se as veias jugulares e as artérias carótidas para sangria. Imediatamente após o abate e evisceração, obteve-se o rendimento de carcaça quente (RCQ) e em seguida, o trato digestório foi esvaziado e pesado para obtenção 
do peso corporal vazio $(\mathrm{PCV}=\mathrm{PVA}$-conteúdo do trato digestório) e do rendimento verdadeiro ou biológico $\left(\mathrm{RV}=\mathrm{PCQ} / \mathrm{PCV}^{*} 100\right)$. Em seguida, as carcaças foram transferidas para câmara fria a $4^{\circ} \mathrm{C}$ onde permaneceram por 24 horas, penduradas pelos tendões do Gastrocnêmio, em ganchos apropriados, para manutenção das articulações tarso-metatarsianas distanciadas em $17 \mathrm{~cm}$.

Ao final desse período, as carcaças foram pesadas, para obtenção do peso da carcaça fria (PCF) e calculados a perda de peso pelo resfriamento (PPR) e o rendimento de carcaça fria ou comercial (RC). Posteriormente, as carcaças foram divididas longitudinalmente e, a metade esquerda foi seccionada em seis regiões anatômicas que foram pesadas individualmente, determinandose as porcentagens que representaram o todo: paleta, região que compreende a escápula, úmero, ulna, rádio e carpo; pescoço, região que compreende as sete vértebras cervicais; costelas, região da primeira à décima terceira costela (vértebras torácicas); lombo, região que compreende as vértebras lombares; perna, com base óssea nas vértebras sacras e duas primeiras vértebras coccígeas, ílio, ísquio, púbis, fêmur, tíbia e tarso; baixos, obtido traçando-se uma linha reta da borda dorsal do abdome à ponta do esterno. Os cortes lombo e perna foram embalados em sacos plásticos e armazenados em freezer a $-18^{\circ} \mathrm{C}$ durante 3 meses, quando então foram descongelados por 20 horas a $10^{\circ} \mathrm{C}$ em geladeira para serem dissecados.

$\mathrm{Na}$ dissecação, foram separados os seguintes grupos de tecidos: músculos, ossos, gordura subcutânea ou gordura externa, localizada abaixo da pele, gordura intermuscular, abaixo da fáscia profunda e outros, constituído por fáscias, tendões, vasos sanguíneos, glândula e nervos. Após a dissecação foram calculadas as proporções destes tecidos nos cortes. Da perna foi obtido o músculo Semimenbranosus e do lombo, o músculo Longissimus lumborum para determinação de cor, capacidade de retenção de água (CRA), perdas por cocção (PPC) e força de cisalhamento (FC). No músculo Longissimus lumborum, na altura da $13^{\mathrm{a}}$ vértebra torácica, foram efetuadas mensurações para o cálculo da área de olho de lombo (AOL), de acordo com Silva Sobrinho (1999), em que a escolha deste músculo deve-se ao fato de que o mesmo apresenta maturação tardia e fácil mensuração, estimando com confiabilidade o desenvolvimento e tamanho do tecido muscular, sendo tomadas quatro medidas: medida A (comprimento máximo do músculo); medida B (profundidade máxima do músculo); medida C (espessura mínima de gordura de cobertura sobre o músculo) e medida GR (espessura máxima de gordura de cobertura sobre a superfície da $13^{\mathrm{a}}$ costela, a $11 \mathrm{~cm}$ da linha dorso-lombar).A cor foi obtida pelos valores das coordenadas $\mathrm{L}^{*}$ (luminosidade), a* (intensidade de vermelho) e $\mathrm{b}^{*}$ (intensidade de amarelo) que foram medidas utilizando-se o colorímetro Minolta CR-200.

A capacidade de retenção de água foi determinada conforme metodologia adaptada de Hamm citado por Silva Sobrinho (1999). As amostras de carne foram pesadas e colocadas sobre papel filtro entre duas placas acrílicas, e sobre estas, um peso de 10 $\mathrm{kg}$ durante 5 minutos. A amostra de carne prensada foi então pesada, e por diferença, calculada a quantidade de água perdida, sendo o resultado expresso em porcentagem.

Para determinação das perdas de peso no cozimento, as amostras foram pesadas antes e após cozimento em forno pré-aquecido a $170^{\circ} \mathrm{C}$, até atingirem $75^{\circ} \mathrm{C}$ de temperatura interna. Posteriormente, das amostras cozidas foram retiradas subamostras, medindo-se a área $\mathrm{em}^{2}$ para determinação da maciez, no aparelho Texture Analyser acoplado ao dispositivo Warner-Bratzler, o qual mediu a força de cisalhamento da amostra, em kgf (quilograma força).

O delineamento experimental utilizado foi o inteiramente casualizado e para as análises da composição tecidual e das características qualitativas da carne, foi decomposto em modelo fatorial 3 x 2 (três rações e dois cortes). Os dados 
foram submetidos à análise de variância pelo procedimento GLM do pacote estatístico SAS (SAS, 1996) a 5\% de significância, utilizando os seguintes modelos matemáticos:

$Y i j=\mu+T i+e i j$

Yij $=$ valor observado da variável estudada no indivíduo $\mathrm{j}$, recebendo a ração $\mathrm{i}$;

$\mu=$ constante geral;

$\mathrm{Ti}=$ efeito da ração $\mathrm{i}$;

eij = erro aleatório associado a cada observação

Yij.

$\mathrm{Y}_{\mathrm{ijk}}=\mu+\mathrm{D}_{\mathrm{i}}+\mathrm{C}_{\mathrm{j}}+\mathrm{DC}_{\mathrm{ij}}+\mathrm{e}_{\mathrm{ijk}}$

$\mathrm{Y}_{\mathrm{ijk}}=$ valor observado da variável estudada no

indivíduo $\mathrm{k}$, recebendo a ração $\mathrm{i}$;

$\mu=$ constante geral;

$\mathrm{D}_{\mathrm{i}}=$ efeito da ração $\mathrm{i}$;

$\mathrm{C}_{\mathrm{i}}=$ efeito do corte $\mathrm{j}$;

$\mathrm{DC}_{\mathrm{ij}}=$ efeito da interação ração x corte;

$\mathrm{e}_{\mathrm{ij}}=$ erro aleatório associado a cada observação $\mathrm{Y}_{\mathrm{ijk}}$.

\section{Resultados e Discussão}

Não foram observadas diferenças $(\mathrm{P}>0,05)$ para peso vivo ao abate (PCA), pesos de carcaça quente (PCQ) e fria (PCF), porcentagem de perda por resfriamento (PPR) e rendimento verdadeiro da carcaça (RVC), entretanto, os valores de rendimento de carcaça comercial (RCC) foram maiores para os animais que não receberam grãos de girassol na ração em relação aos animais que receberam ração contendo $15 \%$ de grãos de girassol, sem haver diferença para as carcaças dos cordeiros alimentados com ração contendo $7,5 \%$ de grãos de girassol (Tabela 2).

Os resultados observados discordam dos encontrados por Grande et al. (2009) que, trabalhando com fornecimento de rações com grãos de oleaginosas sobre as características quantitativas de carcaça de cabritos $3 / 4$ Boer x $1 / 4$ Saanen não observaram efeitos sobre os parâmetros de rendimento verdadeiro e comercial de carcaça.

Tabela 2. Médias, erros-padrão e coeficientes de variação de peso corporal ao abate (PVA), peso de carcaça quente (PCQ), peso de carcaça fria (PCF), porcentagem de perda por resfriamento (PPR), rendimento verdadeiro da carcaça (RVC) e rendimento comercial da carcaça (RCC) de cordeiros terminados em confinamento com rações contendo grãos de girassol.

\begin{tabular}{lcccc}
\hline \multirow{2}{*}{ Parâmetro } & \multicolumn{3}{c}{ Ração $^{\mathbf{1}}$} & \multirow{2}{*}{ CV $^{\mathbf{2}}(\mathbf{\%})$} \\
\cline { 2 - 4 } & $\mathbf{R} \mathbf{\text { R2 }}$ & $31,07 \pm 0,47$ & $\mathbf{R 3}$ & $3,05 \pm 0,36$ \\
PCA (kg) & $30,59 \pm 0,32$ & $14,37 \pm 0,37$ & $14,09 \pm 0,25$ & 5,46 \\
PCQ (kg) & $14,72 \pm 0,28$ & $14,01 \pm 0,33$ & $13,70 \pm 0,26$ & 5,65 \\
PCF (kg) & $14,32 \pm 0,30$ & $2,49 \pm 0,21$ & $2,82 \pm 0,38$ & 29,12 \\
PPR (\%) & $2,69 \pm 0,31$ & $55,99 \pm 0,59$ & $54,41 \pm 0,60$ & 3,44 \\
RVC (\%) & $55,53 \pm 0,84$ & $45,09 \pm 0,75 \mathrm{ab}$ & $44,11 \pm 0,55 \mathrm{~b}$ & 4,73 \\
RCC (\%) & $46,82 \pm 0,79 \mathrm{a}$ &
\end{tabular}

${ }^{1} \mathrm{R} 1=$ ração sem grãos de girassol; R2 = ração contendo 7,5\% de grãos de girassol e R3= ração contendo $15 \%$ de grãos de girassol.

${ }^{2} \mathrm{CV}=$ coeficiente de variação.

* Médias seguidas de letras diferentes na mesma linha diferem pelo teste de Tukey a 5\% de probabilidade.

Fonte: Elaboração dos autores.

Observou-se que os cortes comerciais da carcaça de cordeiros recebendo rações contendo grãos de girassol não diferiram em relação às carcaças de cordeiros que não receberam grãos de girassol na ração (Tabela 3). Os resultados encontrados estão em acordo com os obtidos por Louvandini et al. (2007) que, fornecendo farelo de girassol em substituição ao farelo de soja para ovinos Santa Inês não observaram diferenças nos rendimentos de cortes das carcaças de cordeiros recebendo 
diferentes quantidades de farelo de girassol. Souza et al. (2008) também não observaram diferenças no rendimento de cortes comerciais de ovinos alimentados com silagem de girassol e de milho. Esses resultados confirmam o que Boccard e
Dumont (1960) descreveram na clássica lei da harmonia anatômica, em que as proporções relativas das diferentes regiões corporais são semelhantes em carcaças de peso e estado de gorduramento similares.

Tabela 3. Médias, erros-padrão e coeficientes de variação das porcentagens de cortes comerciais da meia carcaça de cordeiros terminados em confinamento com rações contendo grãos de girassol.

\begin{tabular}{lcccc}
\hline \multirow{2}{*}{ Parâmetro (\%) } & \multicolumn{3}{c}{ Raçã $^{\mathbf{1}}$} & \multirow{2}{*}{ CV $^{2}(\%)$} \\
\cline { 2 - 4 } & $\mathbf{R} \mathbf{\%}$ & $\mathbf{R 2}$ & $\mathbf{R 3}$ & 5,73 \\
Paleta & $19,19 \pm 0,37$ & $19,97 \pm 0,58$ & $19,84 \pm 0,33$ & 10,08 \\
Pescoço & $8,61 \pm 0,28$ & $7,92 \pm 0,33$ & $8,07 \pm 0,34$ & 6,40 \\
Costelas & $15,30 \pm 0,38$ & $14,39 \pm 0,27$ & $14,82 \pm 0,31$ & 5,69 \\
Lombo & $10,31 \pm 0,19$ & $10,70 \pm 0,24$ & $10,77 \pm 0,27$ & 2,65 \\
Perna & $34,87 \pm 0,35$ & $35,27 \pm 0,25$ & $34,97 \pm 0,47$ & 9,88 \\
Baixos & $11,72 \pm 0,63$ & $11,75 \pm 0,19$ & $11,87 \pm 0,24$ & \\
\hline
\end{tabular}

${ }^{1} \mathrm{R} 1=$ ração sem grãos de girassol; R2 = ração contendo 7,5\% de grãos de girassol e R3= ração contendo $15 \%$ de grãos de girassol.

${ }^{2} \mathrm{CV}=$ coeficiente de variação.

* Médias não diferiram pelo teste Tukey a 5\% de probabilidade.

Fonte: Elaboração dos autores.

Com relação às mensurações do músculo Longissimus lumborum (Tabela 4), não houve diferença nas medidas de comprimento máximo (A), profundidade máxima do músculo (B), espessura mínima de gordura de cobertura sobre o músculo (C), espessura máxima de gordura de cobertura sobre a superfície da $13^{\mathrm{a}}$ costela, a $11 \mathrm{~cm}$ da linha dorso- lombar (GR) e área de olho de lombo (AOL) entre os lombos de cordeiros que receberam diferentes rações. Estes resultados encontram-se em concordancia com os observados por Macedo et al. (2008) que não observaram diferenças quando forneceram rações contendo sementes de girassol para cordeiros, com resultados próximos aos obtidos neste estudo.

Tabela 4. Mensurações no músculo Longissimus lumborum de cordeiros terminados em confinamento com rações contendo grãos de girassol.

\begin{tabular}{|c|c|c|c|c|}
\hline \multirow{2}{*}{ Parâmetro } & \multicolumn{3}{|c|}{ Ração $^{1}$} & \multirow{2}{*}{$\mathrm{CV}^{2}(\%)$} \\
\hline & R1 & R2 & R3 & \\
\hline $\mathrm{A}(\mathrm{cm})$ & $5,53 \pm 0,12$ & $5,37 \pm 0,15$ & $5,42 \pm 0,12$ & 6,29 \\
\hline $\mathrm{B}(\mathrm{cm})$ & $2,82 \pm 0,16$ & $2,65 \pm 0,13$ & $2,45 \pm 0,11$ & 14,63 \\
\hline $\mathrm{C}(\mathrm{cm})$ & $0,25 \pm 0,018$ & $0,22 \pm 0,001$ & $0,23 \pm 0,012$ & 17,09 \\
\hline GR (cm) & $0,65 \pm 0,06$ & $0,62 \pm 0,06$ & $0,63 \pm 0,09$ & 29,54 \\
\hline $\operatorname{AOL}\left(\mathrm{cm}^{2}\right)$ & $12,29 \pm 0,76$ & $11,23 \pm 0,70$ & $10,42 \pm 0,44$ & 16,55 \\
\hline
\end{tabular}

${ }^{1} \mathrm{R} 1=$ ração sem grãos de girassol; R2 = ração contendo 7,5\% de grãos de girassol e R3= ração contendo $15 \%$ de grãos de girassol. ${ }^{2} \mathrm{CV}=$ coeficiente de variação.

A - comprimento máximo do músculo B - profundidade máxima do músculo; C - espessura mínima de gordura de cobertura sobre o músculo Longissimus lumborum; GR- espessura máxima de gordura de cobertura sobre a superfície da $13^{\mathrm{a}} \mathrm{costela}$, a $11 \mathrm{~cm}$ da linha dorso-lombar.

* Médias não diferiram pelo teste Tukey a 5\% de probabilidade.

Fonte: Elaboração dos autores. 
A medida GR obtida foi de $0,633 \mathrm{~cm}$ no lombo dos cordeiros, inferior aos $0,73 \mathrm{~cm}$ obtido por Yamamoto (2006) em cordeiros 7/8 Ile de France 1/8 Ideal alimentados com silagem de resíduos de peixe e superior aos $0,32 \mathrm{~cm}$ obtidos por Siqueira e Fernandes (2000) em cordeiros Corriedale. Esta medida permite avaliar melhor o perfil da distribuição da gordura de cobertura, sendo tomada no ponto em que a gordura apresenta maior espessura.

Os valores observados para área de olho de lombo (AOL) encontram-se dentro da média dos relatados por outros pesquisadores (MACEDO et al., 2008; VIANA, 2011). Comparando rações contendo grãos de oleaginosas, Grande et al. (2009) observaram valores superiores para a AOL em caprinos recebendo dieta contendo grãos de girassol em relação às dietas controle, contendo linhaça e canola, embora não tenham observado diferenças entre os tratamentos.

Houve efeito $(\mathrm{P}<0,05)$ da ração sobre as proporções de músculos, gordura total, outros (fáscias, tendões, vasos sanguíneos, glândula e nervos) e relação músculo:gordura (Tabela 5). A proporção de gordura total dos cortes comerciais das carcaças dos cordeiros alimentados com ração contendo $15 \%$ de grãos de girassol foi superior $(20,15 \%)$ aos das carcaças dos cordeiros alimentados com a ração controle (16,63\%), provavelmente devido ao maior teor de extrato etéreo $(9,61 \%)$ na ração contendo $15 \%$ de grãos de girassol. Consequentemente, a proporção de músculo, assim como a relação músculo:gordura foi maior nos cortes de carcaças de cordeiros que receberam a ração sem adição de grãos de girassol.

A composição tecidual dos cortes do lombo e da perna diferiu, sendo que a perna apresentou maior proporção de músculo $(67,27 \%)$ em relação ao lombo $(57,14 \%)$, e maiores relações músculo:osso e músculo:gordura (Tabela 5). Pereira (2011) encontrou valores médios de proporção de músculo (49,34\%) na perna de cordeiros Santa Inês alimentados com farelo de mamona destoxificado, com baixa relação músculo:osso $(2,25)$ e músculo:gordura $(4,09)$ semelhantes aos obtidos neste estudo. Siqueira, Simões e Fernandes (2001) encontraram relação músculo:osso de 2,0 para o lombo de cordeiros $1 / 2$ Ile de France $1 / 2$ Corriedale abatidos aos $32 \mathrm{~kg}$ de peso corporal.

Tabela 5. Médias e coeficientes de variação das proporções dos componentes teciduais do lombo e perna de cordeiros terminados em confinamento com rações contendo grãos de girassol.

\begin{tabular}{lcccccc}
\hline \multirow{2}{*}{ Parâmetro } & \multicolumn{5}{c}{ Raçã $^{\mathbf{1}}$} & \multicolumn{2}{c}{ Corte } & \multirow{2}{*}{ CV $^{2}(\%)$} \\
\cline { 2 - 5 } & $\mathbf{R} 1$ & $\mathbf{R 2}$ & $\mathbf{R 3}$ & Lombo & Perna & \\
\hline Músculos (\%) & $63,15 \mathrm{a}$ & $61,65 \mathrm{~b}$ & $61,82 \mathrm{ab}$ & $57,14 \mathrm{~b}$ & $67,27 \mathrm{a}$ & 9,86 \\
Gordura Total (\%) & $16,63 \mathrm{~b}$ & $19,19 \mathrm{ab}$ & $20,15 \mathrm{a}$ & $23,18 \mathrm{a}$ & $14,14 \mathrm{~b}$ & 31,29 \\
Gord. Sub.(\%) & 9,87 & 11,43 & 11,80 & $13,28 \mathrm{a}$ & $8,79 \mathrm{~b}$ & 34,21 \\
Gord. Inter. (\%) & 6,46 & 7,75 & 8,35 & $9,89 \mathrm{a}$ & $5,35 \mathrm{~b}$ & 47,00 \\
Ossos (\%) & 17,66 & 16,76 & 16,13 & 17,09 & 16,61 & 19,47 \\
Outros (\%) & $2,55 \mathrm{a}$ & $2,40 \mathrm{ab}$ & $1,89 \mathrm{~b}$ & $2,58 \mathrm{a}$ & $1,98 \mathrm{~b}$ & 45,15 \\
Músculo:Osso & 3,65 & 3,89 & 3,93 & $3,57 \mathrm{~b}$ & $4,08 \mathrm{a}$ & 21,53 \\
Músculo:Gordura & $4,27 \mathrm{a}$ & $3,58 \mathrm{~b}$ & $3,42 \mathrm{~b}$ & $2,60 \mathrm{~b}$ & $4,92 \mathrm{a}$ & 39,48 \\
\hline
\end{tabular}

${ }^{1} \mathrm{R} 1=$ ração sem grãos de girassol; R2 = ração contendo 7,5\% de grãos de girassol e R3= ração contendo $15 \%$ de grãos de girassol.

${ }^{2} \mathrm{CV}=$ coeficiente de variação.

* Médias seguidas de letras diferentes na mesma linha diferem pelo teste de Tukey a 5\% de probabilidade.

Fonte: Elaboração dos autores. 
Os parâmetros de cor, capacidade de retenção de água (CRA), perdas por cocção (PPC) e força de cisalhamento não apresentaram diferenças nas carnes dos cordeiros alimentados com as diferentes rações (Tabela 6). Em relação aos músculos Longissimus lumborum e Semimembranosus, obtidos dos cortes do lombo e da perna, respectivamente, observou-se diferença $(\mathrm{P}<0,05)$ para todos os parâmetros qualitativos avaliados. A CRA do músculo Longissimus lumborum foi superior ao do músculo Semimembranosus, observando-se também menor força de cisalhamento, proporcionando assim maior maciez e suculência para a carne.

O desenvolvimento tardio do músculo Longissimus lumborum em relação ao músculo Semimembranosus, pode justificar a maior intensidade de luminosidade encontrado no $L$. lumborum, e a menor intensidade de vermelho (a) (Tabela 6). A maior atividade desenvolvida pelo músculo Semimembranosus pode influenciar diretamente na sua coloração, fazendo com que esta apresente maior intensidade de vermelho em relação ao músculo Longissimus lumborum.

Os resultados obtidos para perdas por cocção (PPC) estão de acordo com os observados por Pinheiro et al. (2009), na avaliação da qualidade da carne de cordeiros, entretanto, a força de cisalhamento (FC) divergiu dos apresentados por tais pesquisadores, uma vez que os mesmos encontraram valores de força de cisalhamento dos músculos L. lumborum e Semimembranosus iguais a $1,79 \mathrm{kgf} / \mathrm{cm}^{2}$ e $1,30 \mathrm{kgf} / \mathrm{cm}^{2}$, respectivamente, inferior aos obtidos neste estudo.

Tabela 6. Médias e coeficientes de variação dos parâmetros qualitativos da carne de cordeiros terminados em confinamento com rações contendo grãos de girassol.

\begin{tabular}{|c|c|c|c|c|c|c|}
\hline \multirow{2}{*}{ Parâmetro } & \multicolumn{3}{|c|}{ Ração $^{1}$} & \multicolumn{2}{|c|}{ Músculo } & \multirow{2}{*}{$C V^{2}(\%)$} \\
\hline & R1 & R2 & $\mathbf{R 3}$ & L. lumborum & Semimemb. & \\
\hline \multicolumn{7}{|l|}{ Cor } \\
\hline $\mathrm{L}$ & 39,89 & 40,51 & 40,03 & $41,59 a$ & $38,69 b$ & 6,07 \\
\hline $\mathrm{a}$ & 15,25 & 15,40 & 15,84 & $14,58 b$ & $16,41 \mathrm{a}$ & 8,68 \\
\hline $\mathrm{b}$ & 2,58 & 2,92 & 3,13 & $3,75 a$ & $2,00 \mathrm{~b}$ & 48,91 \\
\hline CRA (\%) & 59,05 & 59,72 & 58,44 & $60,38 \mathrm{a}$ & $57,76 \mathrm{~b}$ & 5,27 \\
\hline $\mathrm{PPC}(\%)$ & 39,06 & 38,47 & 39,60 & $41,02 \mathrm{a}$ & $37,07 b$ & 10,22 \\
\hline $\mathrm{FC}(\mathrm{Kgf})$ & 7,78 & 6,68 & 6,98 & $6,04 b$ & $8,25 \mathrm{a}$ & 32,92 \\
\hline $\mathrm{FC}\left(\mathrm{Kgf} / \mathrm{cm}^{2}\right)$ & 2,89 & 2,57 & 2,52 & $2,21 \mathrm{~b}$ & $3,10 \mathrm{a}$ & 41,69 \\
\hline
\end{tabular}

${ }^{1} \mathrm{R} 1=$ ração sem grãos de girassol; R2 = ração contendo 7,5\% de grãos de girassol e R3= ração contendo $15 \%$ de grãos de girassol ${ }^{2} \mathrm{CV}=$ coeficiente de variação.

L - luminosidade; a- intensidade de vermelho; b- intensidade de amarelo; CRA- capacidade de retenção de água; PPC- perdas por cocção; FC- força de cisalhamento.

* Médias seguidas de letras diferentes na mesma linha diferem pelo teste de Tukey a 5\% de probabilidade.

Fonte: Elaboração dos autores.

\section{Conclusões}

A inclusão de grãos de girassol na dieta de cordeiros em confinamento não altera as características quantitativas da carcaça, porém aumenta a deposição de gordura nas carcaças e diminui a relação músculo:gordura das mesmas. $\mathrm{O}$ músculo Longissimus lumborum apresenta maior maciez em relação ao músculo Semimembranosus.

\section{Referências}

ANGELINE, A. C.; ÚNGARO, M. R. G.; ANDRADE, N. de O.; DENUCCI, S. Girassol, uma planta versátil. 
Campinas: CECOR/CATI, 1998. (Cati Responde, n. 30). Disponível em: $<$ http://www.cati.sp.gov.br>. Acesso em: 20 jul. 2004.

BOCCARD, R.; DUMONT, B. L. Etude de la production de viande chez les ovins. II. Variation de l'importance relative des differentes regions corporalles des agneaux de boucherie. Annales de Zootechnie, Paris, v. 9, n. 4, p. $355-365,1960$.

BUENO, M. S.; CUNHA, E. A.; SANTOS, L. E.; RODA, D. S.; LEINZ, F. F. Características de carcaças de cordeiros Suffolk abatidos em diferentes idades. Revista Brasileira de Zootecnia, Viçosa, v. 29, n. 6, p. 1803-1810, 2000.

COLLOMB, M.; SOLLBERGER, H.; BUTIKOFER, U.; SIEBER, R.; STOLL, W.; SCHAEREN, W. Impact of a basal diet of hay and fodder beet supplemented with rapessed, linseed and sunflower seed on the acid composition of milk fat. International Dairy Journal, Switzerland, v. 14, n. 6, p. 549-559, 2004.

GARCIA, I. F. F.; PEREZ, J. R. O.; OLIVEIRA, M. V. Características de carcaça de cordeiros Texel $\mathrm{x}$ Bergamácia, Texel x Santa Inês e Santa Inês Puros, terminados em confinamento, com casca de café como parte da dieta. Revista Brasileira de Zootecnia, Viçosa, v. 30, n. 3, p. 253-260, 2000.

GRANDE, P. A.; ALCADE, C. R.; LIMA, L. S.; AYER, I. M.; MACEDO, F. A. F.; MATSUSHITA, M. Características quantitativas da carcaça e qualitativas do músculo Longissimus dorsi de cabritos 3/4 Boer $+1 / 4$ Saanen confinados recebendo rações contendo grãos de oleaginosas. Revista Brasileira de Zootecnia, Viçosa, v. 38, n. 6, p. 1104-1113, 2009.

KOOHMARAIE, M.; WHIPPLE, G.; CROUSE, J. D. Acceleration of post mortem tenderization in lamb and Brahman-cross beef carcasses through infusion of calcium chloride. Journal of Animal Science, Champaign, v. 68, n. 5 , p. $1278-1283,1990$.

LOUVANDINI, H.; NUNES, G. A.; GARCIA, J. A. S.; MCMANUS, C.; COSTA, D. M.; ARAÚJO, S. C. Desempenho, características de carcaça e constituintes corporais de ovinos Santa Inês alimentados com farelo de girassol em substituição ao farelo de soja na dieta. Revista Brasileira de Zootecnia, Viçosa, v. 36, n. 3, p. 603-609, 2007.

MACEDO, V. P.; GARCIA, C. A.; SILVEIRA, A. C.; MONTEIRO, A. L. G.; MACEDO, F. A. F.; SPERS, R. C. Composições tecidual e química do lombo de cordeiros alimentados com rações contendo sementes de girassol em comedouros privativos. Revista Brasileira de Zootecnia, Viçosa, v. 37, n. 10, p. 1860-1868, 2008.
OLIVEIRA, M. V. M.; PÉREZ, J. R. O.; ALVES, E. L.; MARTINS, A. R. V.; LANA, R. P. Rendimento de carcaça, mensurações e peso de cortes comerciais de cordeiros Santa Inês e Bergamácia alimentados com dejetos de suínos em confinamento. Revista Brasileira de Zootecnia, Viçosa, v. 31, n. 3, p. 1451-1458, 2002.

PARDI, M. C.; SANTOS, I. F.; SOUZA, E. R.; PARDI, H. S. Ciência, higiene e tecnologia da carne. 2. ed. Goiânia: UFG, 2001. 623 p.

PELICANO, E. R. L.; SOUZA, P. A. de. Composição físico-química \& valor nutricional de carnes. Jaboticabal: Universidade Estadual Paulista, 2004. 44 p.

PEREIRA, M. S. C. Características da carcaça e da carne de cordeiros Santa Inês alimentados com farelo de mamona destoxificado. 2011. Dissertação (Mestrado em Zootecnia) - Universidade Federal do Ceará, Fortaleza.

PINHEIRO, R. S. B.; SILVA SOBRINHO, A. G.; SOUZA, H. B. A.; YAMAMOTO, S. M. Qualidade de carnes provenientes de cortes da carcaça de cordeiros e de ovinos adultos. Revista Brasileira de Zootecnia, Viçosa, v. 38, n. 9, p. 1790-1796, 2009.

STATISTICAL ANALYSIS SYSTEMS - SAS. User's guide. North Caroline: SAS Institute Inc., 1996.

SILVA SOBRINHO, A. G. Body composition and characteristics of carcass from lambs of different genotypes and ages at slaughter. 1999. (Post Doctorate in Sheep Meat Production) - Massey University, Palmerston North.

SILVA, L. F.; PIRES, C. C. Avaliações quantitativas e predição das proporções de osso, músculo e gordura da carcaça em ovinos. Revista Brasileira de Zootecnia, Viçosa, v. 29, n. 4, p. 1253-1260, 2000.

SIQUEIRA, E. R.; FERNANDES, S. Efeito do genótipo sobre as medidas objetivas e subjetivas da carcaça de cordeiros terminados em confinamento. Revista Brasileira de Zootecnia, Viçosa, v. 29, n. 1, p. 306-311, 2000.

SIQUEIRA, E. R.; SIMÕES, C. D.; FERNANDES, S. Efeito do sexo e do peso ao abate sobre a produção de carne de cordeiro. Morfometria da carcaça, pesos dos cortes, composição tecidual e componentes não constituintes da carcaça. Revista Brasileira de Zootecnia, Viçosa, v. 30, n. 4, p. 1299-1307, 2001.

SOUZA,V. S.; LOUVANDINI, H.; SCROPFNER, E. S.; MCMANUS, C. M.; ABDALLA, A. L.; GARCIA, J. A. S. Desempenho, características de carcaça e componentes corporais de ovinos deslanados alimentados com silagem de girassol e silagem de milho. Ciência Animal Brasileira, Goiânia, v. 9, n. 2, p. 284-291, 2008. 
VIANA, P. G. Desempenho e características de cacarça de ovinos Santa inês suplementados com caroço de algodão (Gossypium ssp.) e seus co-produtos. 2011. Dissertação (Mestrado em Ciências Animais) Universidade de Brasília, Brasília.
YAMAMOTO, S. M. Desempenho e características da carcaça e da carne de cordeiros terminados em confinamento com dietas contendo silagens de resíduos de peixes. 2006. Tese (Doutorado em Zootecnia) Universidade Estadual Paulista, Jaboticabal. 